\title{
The Interpretative Flexibility, Instrumental Evolution and Institutional Adoption of Mathematical Software in Educational Practice: The Examples of Computer Algebra and Dynamic Geometry
}

\author{
Kenneth Ruthven
}

\section{University of Cambridge}

\begin{abstract}
This paper examines three important facets of the incorporation of new technologies into educational practice, focusing on emergent usages of the mathematical tools of computer algebra and dynamic geometry. First, it illustrates the interpretative flexibility of these tools, highlighting important differences in ways of conceptualizing and employing them that reflect their appropriation to contrasting practices of mathematics teaching. Second, it examines the cultural process of instrumental evolution in which mathematical frameworks and teaching practices are adapted in response to new possibilities created by these tools, showing that such evolution remains at a relatively early stage. Third, it points to crucial prerequisites, at both classroom and systemic levels, for effective institutional adoption of such tools: explicit recognition of the interplay between the development of instrumental and mathematical knowledge, including the establishment of a recognized repertoire of toolmediated mathematical techniques supported by appropriate discourses of explanation and justification.
\end{abstract}

Keywords: computer algebra; dynamic geometry; mathematics teaching; secondary schools; sociocultural analysis; technology integration.

\section{The Incorporation of New Technologies in Educational Practice as a Process of Appropriation}

This paper examines three important facets of the incorporation of new technologies into educational practice: interpretative flexibility, instrumental evolution, and institutional adoption. While it focuses on the particular case of secondary-school mathematics, and the specific examples of computer algebra and dynamic geometry, the sociocultural concepts which it employs have a much wider applicability. Essentially, they are valuable in analyzing crucial aspects of the appropriation of new tools to curricular purposes and teaching practices. From this perspective, appropriation is treated not simply as a matter of adopting a tool and developing capacity for using it, but as a process by which the tool is integrated into a wider cultural practice. In particular, this process of integration is seen as involving reciprocal adaptation. On the one hand, the way in which a new tool is applied to existing tasks is shaped by already established approaches. On the other hand, as users internalize the mediation of such tasks by the new tool and make corresponding adjustments, this opens the way to more substantial changes of approach.

\section{The Developmental Histories of Computer Algebra and Dynamic Geometry in Educational Practice}

There is an important difference between the developmental histories of the two forms of mathematical software to be considered: dynamic geometry has been formulated more explicitly and designed more deliberately for educational use, whereas computer algebra has been developed primarily to meet the needs of professional mathematicians, even if some recent versions have been adapted for an educational market (Hoyles \& Noss, 2003). Thus, 
while both technologies have been the focus of exploratory projects piloting their use at secondary-school level, the mainstream uptake of dynamic geometry has been more longstanding and more widespread. In particular, whereas several studies have now been undertaken of the classroom practice of ordinary teachers using dynamic geometry under everyday circumstances (e.g. Engström, 2004; Lins, 2003; Ruthven, Hennessy \& Deaney, 2008), similar studies are currently lacking for computer algebra, although the classroom practice of teachers involved in pilot projects has been examined (e.g. Artigue, 2002; Kendal, Stacey \& Pierce, 2005).

\section{The Interpretative Flexibility of Technologies: Design Continues in Usage}

However established the physical and operational prototype for a tool, however accepted the expectations about aims and methods for its use, there is scope for these to be expanded and adapted, reshaped or reconceived. This 'interpretative flexibility' which surrounds any technology can be seen in the varied conceptions of its functionalities and modes of use which come into play, not only during its evolving design, but in the course of its propagation as a finished product, and of its appropriation as a practical tool (Kline \& Pinch, 1999; Williams \& Edge, 1996). In particular, the process through which a technology becomes aligned with user concerns and adapted to use settings opens the way to variation in conceptions and usages between different user groups, and to change in these over time (which may, in turn, precipitate redesign of the tool). In this sociocultural model, "design continues in usage" (Rabardel \& Bourmaud, 2003, p. 666), and "the conceptualization of instruments [is] an activity distributed between designers and users" (Rabardel \& Waern, 2003, p. 643). In particular, teachers interpret educational resources and mediate their students' use of them (Haggarty \& Pepin, 2002; Remillard, 2005); they necessarily incorporate such materials into wider systems of classroom practice, so that, rather than determining such practice, the designs of their developers turn out to be only one component of it (Ball \& Cohen, 1996). Various aspects of this interpretative flexibility will be illustrated in the next five sections of the paper.

\section{The Interpretative Flexibility of Dynamic Geometry: From Innovative Advocacy to Mainstream Uptake}

Innovative advocacy for dynamic geometry has cast it as a means of supporting approaches to school mathematics based on relatively open student exploration, experimentation and investigation (Balacheff \& Kaput, 1996; Chazan \& Yerushalmy, 1995; Hoyles \& Noss, 2003). However, pioneering projects have shown that teachers find it challenging to conceive appropriate tasks, and to manage student traversal of a mathematics curriculum organized in such a way (Laborde, 2001; Lampert, 1993; Wiske \& Houde, 1993). Indeed, the findings of a substantial national survey conducted in the United States identified an apparent enigma. While many high-school mathematics teachers nominated Geometer's Sketchpad as their most valued software, they tended also to report skill-development as their main objective for computer use (Becker, Ravitz \& Wong, 1999). This enigma is illuminated by a more recent English study of the incorporation of dynamic geometry into mainstream practice which found that many teachers saw dynamic geometry as helping to make forms of guided discovery viable in the classroom, typically through structured 'investigations' aimed at establishing standard results (Ruthven, Hennessy \& Deaney, 2008).

\section{Diverging Modes of Dynamic Geometry Use in the Classroom: The Place of Student Experience and Apparent Anomaly}

This English study also found interpretative flexibility running across teacher users in the form of significant variability in their approaches to the classroom use of dynamic geometry. 
These differences were associated with contrasting conceptions of the software and linked to more general divergences of teaching approach. First, the degree to which teachers planned for students themselves to experience use of the software was influenced by the extent to which this was seen as involving students in mathematically disciplined interaction with an inherently geometric system. Second, the way in which teachers handled apparent mathematical anomalies of software operation was influenced by whether such anomalies were seen as providing opportunities to develop students' mathematical understanding. Such a view was associated, in turn, with a more fundamental pedagogical orientation in which analysis of mathematical discrepancies was seen as supporting students' learning. This variability is illustrated by the contrasting classroom approaches followed by two teachers in their lessons on the angle sums of polygons. In one lesson, the development of ideas was organized around teacher-led presentation and questioning, with the teacher taking sole responsibility for operating the software and exercising great care to avoid exposing students to apparent anomalies in its operation (such as those relating to measurement of reflex angles and rounding of results, as shown in Figure 1). In the other lesson, the development of ideas was organized around task-focused use of the software by students, structured and shaped by the teacher in ways considered beneficial for building mathematical knowledge -including having students construct figures for themselves, and expecting them to identify apparent anomalies of operation and try to make mathematical sense of them.

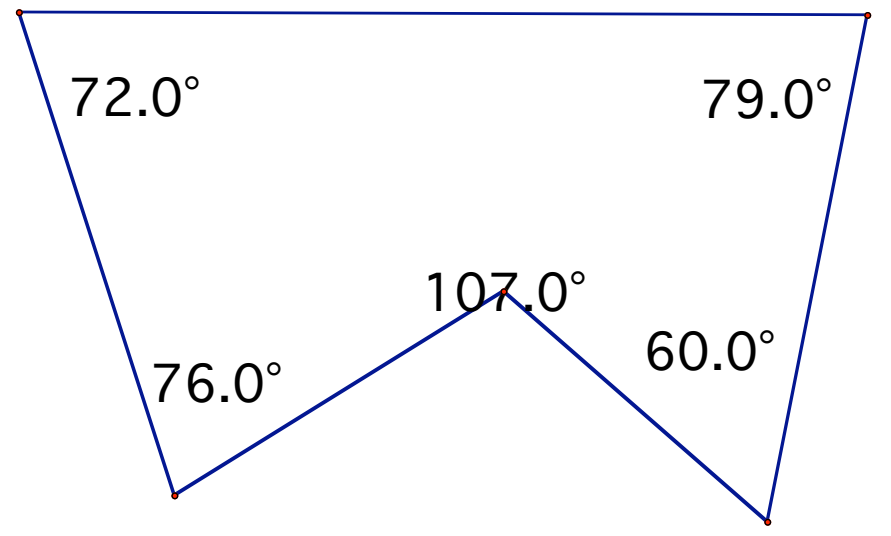

Angle sum $=394.1^{\circ}$

Figure 1: Apparent mathematical anomalies in a dynamic geometry investigation

\section{Diverging Modes of Dynamic Geometry Use: The Choice of Mathematical Register and Reasoning Modality}

Much of the pioneering development of dynamic geometry systems has taken place in countries - notably France and the United States - which have retained a classical Euclidean spirit within their school geometry curriculum (Hoyles, Foxman \& Küchemann, 2001). However, the scope to employ the software as a means of supporting observation and experiment resonates with the more empirical style found in many systems (Hoyles, Foxman \& Küchemann, 2001; Howson, 1995). In particular, once the scope of dynamic geometry systems had been extended beyond classical methods of construction and transformation to provide tools for measurement and calculation, the software became well adapted to empirical approaches in which geometric properties are established through induction from arithmetic patterns. Given that such an approach is well established in English secondary-school mathematics (Kaiser, 2002), where the national curriculum talks of 'shape, space and measures' rather than 'geometry', the use of dynamic geometry to support this modality of reasoning about geometric situations within a primarily arithmetic register (as illustrated in 
Figure 1) was found to be very prevalent in the English study (Ruthven, Hennessy \& Deaney, 2008). Nevertheless, the study also found an outlier case in which a teacher employed dynamic geometry as a means of "going beyond the national curriculum" to work in a directly geometric register, so as to give students access to the classical 'geometry' tradition now largely dormant in English schools. The examples of this section and the last, then, illustrate the role that broader mathematical cultures and teaching practices play in the interpretation and appropriation of dynamic geometry by teachers.

\section{Diverging Modes of Computer Algebra Use: Instrument of Accurate Computation or of Cross-Representational Understanding}

The origins of computer algebra as a tool for professional mathematicians mean that its use at school level necessitates some interpretation of its educational function and value. This is illustrated by the account which Kendal and colleagues (Kendal \& Stacey, 2001; Kendal, Stacey \& Pierce, 2005) provide, from an Australian project, of contrasting approaches taken by teachers to incorporating CAS into their classroom practice. Not only were the two teachers colleagues in the same school department, teaching similar upper secondary classes; they were taking part in the same development project, working together with other members of the project team to plan classroom activities. However, in line with his broader stance of "teaching for performance", one teacher saw computer algebra primarily as a computational tool to help students produce accurate results; his main focus was on providing students with a new set of routine computer algebra procedures for such purposes. The other teacher, in line with his broader stance of "teaching for understanding", saw computer algebra primarily as a pedagogical tool to help students grasp new material; his main focus was on: (a) working with parallel symbolic and graphical representations of functions and their derivatives to bring out relationships between them; and (b) generating patterned results by applying a common operation to sets of symbolic expressions from which general rules could be induced (such as between particular types of expression and their derivatives as shown in Figure 2). Moreover, this teacher restricted students' use of computer algebra for normal computational purposes because he considered that following pencil-and-paper methods was extremely important for developing understanding. Following Wertsch's (1990) use of the term, Kendal et al. talk of the teachers 'privileging' different modes of use for computer algebra, aligned with their differing conceptions of mathematical learning and correspondingly diverging teaching practices.

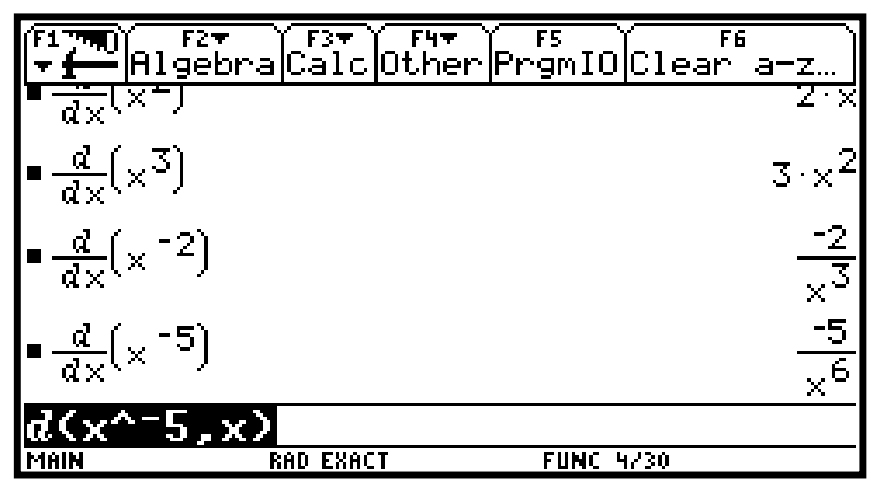

Figure 2: Patterned computation in a computer algebra investigation to induce a general rule

\section{Diverging Modes of Computer Algebra Use: Pragmatic and Epistemic Emphases within Teaching Approaches}

Contrasts in the interpretation of computer algebra as an educational tool also emerge from comparing the approaches adopted by pioneering projects in different countries (Ruthven, 
2002; Fey, 2006). In some respects, these parallel some of the differences in dynamic geometry use noted in an earlier section. The most salient program in the United States has taken a more pragmatic approach in which computer tools are treated as providing a relatively straightforward and convenient vehicle for applied modeling and problem-solving (Fey, Heid, Good, Sheets, Blume \& Zbiek, 1995). In France, by contrast, the main program has taken a more strongly epistemic approach which plays on the sometimes ambiguous operation of computer tools to expose students to situations which deliberately take them beyond their current experience and understanding: for example, students may be confronted with unfamiliar types of function liable to produce deceptive results when treated with a computer algebra system (Artigue, 2002). This approach is skeptical about the received distinction and the perceived opposition - between learning techniques and forming concepts; and thus about too ready an assumption that access to computational technology permits a reduction even an elimination - of the former in favor of the latter (Lagrange, 2001). Thus it emphasizes the interplay between the development of students' mathematical knowledge and their capacity to make use of computer algebra (as will be analyzed and illustrated in the next section).

\section{The Individual Development of Tool-Mediated Mathematical Thinking: The Process of Instrumental Genesis}

The French research community, then, has drawn on an established 'ergonomic' theory (Rabardel, 2002) to analyze the process through which students (and indeed teachers) develop their capacity to make use of a tool for mathematical purposes (Artigue, 2002; Trouche, 2005). In this process of 'instrumental genesis', users develop mental schemes which transform the tool from being simply a material 'artifact' to become a functional 'instrument', used in ways which become progressively more mathematically sophisticated. In particular, users develop schemes concerned not just with immediate operational manipulation of the tool (referred to as 'usage' schemes), but with ulterior mathematical action (referred to as 'instrumented action' schemes). It is this latter aspect which links users' developing mastery of the tool with the wider development of their mathematical knowledge.

\section{Table 1: Components of the instrumented action scheme for solving parameterized equations with a CAS (Drijvers \& Gravemeijer, 2005; p. 174)}

(1) Knowing that the Solve command can be used to express one of the variables in a parameterized equation in other variables.

(2) Remembering the CAS syntax of the Solve command, that is Solve (equation, unknown).

(3) Knowing the difference between an expression and an equation.

(4) Realizing that an equation is solved with respect to an unknown, and being able to identify the unknown in the parameterized problem situation.

(5) Being able to type in the Solve command correctly on the CAS.

(6) Being able to interpret the result, particularly when it is an expression...

For example, working in the Netherlands, Drijvers \& Gravemeijer (2005) have analyzed the instrumented action scheme for solving parameterized equations using a computer algebra tool, breaking it down into the six components shown in Table 1. They point to the way in which 'technical' and 'conceptual' knowledge is intertwined in such a scheme. Moreover, they pinpoint several ways in which of the CAS makes certain concepts explicit which remain implicit when the same task is accomplished 'by hand'. For instance, the concept that an equation is solved with respect to a particular variable is made explicit by CAS syntax for the 
Solve command which requires the user to specify this particular variable, whereas when working with pencil and paper this idea remains tacit because of the absence of a distinct step requiring the method of solution to be formulated in these terms. Likewise, Drijvers \& Gravemeijer report that using the same computer algebra command whether calculating the numerical solution of an equation or making one variable the subject of an equation involving others, fosters awareness of their mathematical equivalence.

\section{Managing the Instrumental Genesis of Computer Algebra Usage: From Unregulated Proliferation to Orchestrated Socialization}

This process of instrumental genesis has a social dimension as well as an individual one. The French research community has drawn on an established 'anthropological' theory (Chevallard, 1992) to conceptualize the wider process through which a mathematical domain is publicly constituted. This theory emphasizes the part which institutionalized systems of recognized tasks and accepted techniques for accomplishing them play in giving meaning to mathematical ideas, and the associated technical and theoretical discourses through which these are explained and justified. It was used to analyze certain difficulties that emerged within a development project to explore the integration of computer algebra into upper secondary mathematics (Artigue, 2002). First and foremost was the explosion of different techniques that computer algebra made available to teachers and students for even the simplest task. Checking an algebraic equivalence, for example, is achievable with a computer algebra system by, amongst many other variants: repeatedly expanding/simplifying the composite expression formed by one side of the equivalence minus the other, to see whether it reduces to zero; or superimposing a graph of the expression from one side of the equivalence on the graph of the other side, to see whether they coincide. In the first year of the French project, the absence of collectively recognized techniques, and of accepted ways of conveying such techniques and sanctioning their use, inhibited the establishment of clear, common lines of mathematical development within the class. By contrast, particular pencil-and-paper techniques had not only an official status, but a well-developed accompanying mathematical discourse for explaining and justifying them. This led the project team to recognize the need to develop some equivalent apparatus to support collective development of mathematical activity through the medium of computer algebra. Likewise, with a view to 'orchestrating' the classroom environment to make it more conducive to such socialization, the project team also gave attention to establishing formats for classroom activity that would counteract the 'privatization' associated with use of symbolic calculators. For example, Trouche (2004; 2005) outlines the role of 'sherpa student' - taken on by a different person from one lesson to the next - who becomes responsible for managing a publicly projected machine; through guiding the actions of this student in front of the whole class, or by opening them up for comment and discussion, the teacher gains a means of shaping use of the tool and the mathematical thinking associated with it.

\section{The Cultural Development of Tool-Mediated Mathematical Thinking: The Process of Instrumental Evolution}

There is, moreover, a larger order of instrumental genesis than the process of individual and collective development through which a group of (student or teacher) users are inducted into a locally shared and mathematically coherent repertoire of tool use. This larger order relates to the process of cultural development, at the level of the community as a whole, through which such a repertoire (and the tool with which it is associated) evolves. Initially, a new technology is likely to be treated as a variant or hybrid of those that are already established and familiar. When a new technology is assimilated to established methods in this way, it functions as an 'amplifier' of existing forms of action rather than as a 'reorganizer' (Dörfler, 1993; Pea, 
1985). Only as distinctive affordances of a new technology are identified and exploited through development of a corresponding system of instrumentation schemes do qualitatively new forms of mathematical action and activity emerge. In the evolution of geometric software, for example, the original idea of a tool to draw accurate geometrical figures was expanded, first through the idea of creating an optional mode in which such figures could be dragged, and then, as the potential of this mode emerged, through it becoming the default one (Scher, 2000). And while the dragging operation relatively rapidly became a defining feature of such software, its unexpected versatility is only gradually being charted and conceptualized (Hölzl, 1996; Arzarello, Olivero, Paola \& Robutti, 2002). I will refer to this cultural process through which new tool-mediated forms of mathematical thinking emerge within a mathematical community, some of which become widely diffused and eventually institutionalized, as one of 'instrumental evolution'.

\section{Degrees of Instrumental Evolution in Dynamic Geometry Usage: From Amplifying Existing Techniques to Reorganizing Mathematical Tasks}

Another French project throws further light on the instrumental evolution of dynamic geometry (Laborde, 2001). Over a period of several years, teachers devised lesson 'scenarios', and iteratively refined them through classroom trials and discussion with a wider team of researchers and developers associated with the software. Laborde identified an evolution of particular scenarios as they were redesigned to incorporate increasing degrees of mathematical/pedagogical innovation. At the first degree, dynamic geometry simply provided a convenient parallel to paper and pencil for producing accurate static diagrams and generating measurement data. At the second degree of innovation, dynamic geometry served to highlight the invariant properties of a dynamic figure: these could be seen to remain stable whilst other characteristics of the figure changed in the course of dragging. Laborde illustrates her typology in terms of the evolution which took place over the course of the project in a scenario intended to introduce students to some geometrical transformation: in the version at he first degree, a dynamic figure consisting of a shape and its image under the given transformation was used simply to generate measurements from several static examples; at the second degree, dragging the dynamic figure was used to support observation aimed at characterizing the transformed image in relation to the original shape. In the final version of the scenario a genuine mathematical problem was created for students to solve in the form of a dynamic figure based on a 'mystery' geometrical transformation, unknown and unfamiliar to the students and accessible to them only through the behavior of the dynamic figure. Here, then, the invariant properties revealed by dragging the figure became the means through which the unknown transformation could be characterized. Laborde reports that types of scenario innovative at this higher degree were developed only by experienced teachers who were very familiar with the use of technology in mathematics teaching and with research in mathematics education. Such scenarios depended on establishing qualitatively new types of solution to familiar problems, or novel forms of problem dependent on the software.

\section{The Institutional Adoption of Dynamic Geometry: From Technological Aspiration to Instrumental Awareness}

These analyses illustrate the complexity and challenge of integrating new mathematical technologies such as dynamic geometry and computer algebra into school mathematics. In particular, they show how central lines of mathematical development need to be rethought if a coherent and effective integration of these tools is to be achieved. Thus, as professional advocacy and official endorsement leads to uptake of these technologies spreading beyond pilot projects into ordinary classrooms, the institutional frameworks and teaching resources which lay out student curriculum and provide pedagogical guidance to teachers need to be 
revised accordingly. For example, in the English study of mainstream usage of dynamic geometry, the marginal way in which its use had been 'bolted on' to an established curriculum helped to explain the limited instrumental evolution in evidence: expressed in terms of teachers cautious about investing time in having their students use (and learn to use) the technology, and usages of dynamic geometry never going beyond the second degree of Laborde's typology. While official guidance elaborating the national curriculum had promoted the use of dynamic geometry, its institutionalization of this remained largely at an aspirational level. First, dynamic geometry tools were treated in a very different way from more established manual tools. For instance, the knowledge and skill required to make use of a protractor to measure angles by hand was carefully specified (Figure 3), whereas there was no equivalent attention to the distinctive knowledge required to measure angles with dynamic software (such as knowing that the measurement tool is applied, not to the line segments forming the arms of an angle, but to the points defining these segments; or knowing that, when an angle of interest becomes reflex under dragging, the measurement provided by the software becomes that of the counterpart minor angle). Thus, while the official guidance explicitly recognized and provided for instrumental induction related to manual tools, it overlooked that aspect of using dynamic geometry tools. Equally, the guidance showed little recognition of how dynamic geometry may open up novel mathematical strategies; its suggested usages assumed mathematical approaches already available with manual tools, or drew explicit parallels with established visual aids. In France, where there have been more substantial programs of officially-sponsored research and development, the official guidance provided for teachers does incorporate a more highly evolved usage of dynamic geometry, but this has had little influence as yet on the textbook schemes which more directly influence classroom practice (Lagrange \& Caliskan-Dedeoglu, in press).

\begin{abstract}
Use a $180^{\circ}$ or $360^{\circ}$ protractor to measure and draw angles, including reflex angles, to the nearest degree. Recognise that an angle can be measured as a clockwise or anticlockwise rotation and that the direction chosen determines which will be the zero line and whether the inner or outer scale is to be used.
\end{abstract}

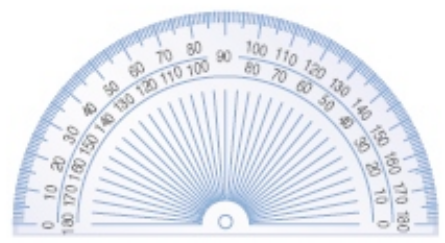

Figure 3: Extract from official 'Framework for Mathematics' focusing on manual tool

\title{
Professional Implications Highlighted by Sociocultural Analysis
}

This paper has identified a range of key issues surrounding the emergent use of computer algebra and dynamic geometry in secondary-school mathematics. First, it has illustrated the interpretative flexibility of these tools by highlighting some important differences which have emerged in ways of conceptualizing and employing them that reflect the appropriation of the tools to contrasting practices of mathematics teaching. Becoming aware of such differences and their wider grounding has professional value in supporting a more nuanced and reflective approach to processes of policy formation, curriculum revision, teacher education, and technology development. Second, this paper has shown that the cultural process of instrumental evolution, in which mathematical frameworks and teaching practices are adapted in response to new possibilities created by these tools, is at a relatively early stage. Indeed, while the studies discussed here have made a useful contribution by highlighting this issue and providing exemplars of more far-reaching reorganization of approaches to teaching 
particular mathematical ideas, this is an area which would benefit from more systematic development on a larger scale: for example, by seeking to re-engineer entire topic modules around new learning trajectories made possible by innovative uses of the tools (e.g. Artigue, 2005). Third, at both classroom and systemic levels, this paper has pointed to crucial prerequisites for effective institutional adoption of such tools. If computer algebra and dynamic geometry are to move from being marginal amplifiers of established practice to become more integral organizers of a renewed practice of school mathematics, this requires an explicit recognition of the interplay between the development of instrumental and mathematical knowledge, including the establishment of a recognized repertoire of instrumented mathematical techniques supported by appropriate discourses of explanation and justification.

\section{ACKNOWLEDGEMENTS}

An earlier version of this paper was presented at the Annual Meeting of the American Educational Research Association, New York, March 2008, to a symposium organized by Sara Hennessy on 'Developing sociocultural theoretical perspectives on teachers' classroom use of digital technologies' sponsored by the SIG - Computer and Internet Applications in Education. The paper draws on research funded by the UK Economic and Social Research Council (award reference R000239823). My thanks go also to the JECR editor and reviewers for their helpful comments and suggestions.

\section{REFERENCES}

Artigue, M. (2002). Learning mathematics in a CAS environment: The genesis of a reflection about instrumentation and the dialectics between technical and conceptual work. International Journal of Computers for Mathematical Learning, 7(3), 245-274.

Artigue, M. (2005). The integration of symbolic calculators into secondary education: Some lessons from didactical engineering. In D. Guin, K. Ruthven, \& L. Trouche, op. cit. (pp. 231-294).

Arzarello, F., Olivero, F., Paola, D., \& Robutti, O. (2002). A cognitive analysis of dragging practises in Cabri environments. Zentralblatt fur Didaktik der Mathematik, 34(3), 66-72.

Balacheff, N., \& Kaput, J. (1996). Computer-based learning environments in mathematics. In A. Bishop et al. (Eds.), International Handbook of Mathematics Education. Dordrecht: Kluwer.

Ball, D. L., \& Cohen, D. K. (1996). Reform by the book: What is -or might be- the role of curriculum materials in teacher learning and instructional reform. Educational Researcher, 25(9), 6-8 \& 14.

Becker, H., Ravitz, J., \& Wong, Y. (1999). Teacher and Teacher-Directed Student Use of Computers, Teaching, Learning, and Computing: 1998 National Survey Report \#3. Centre for Research on Information Technology and Organizations, University of California Irvine.

Chazan, D., \& Yerushalmy, M. (1995). Charting a course for secondary geometry. In R. Lehrer \& D. Chazan (Eds.), New Directions in the Teaching and Learning of Geometry. Hillsdale NJ: Lawrence Erlbaum.

Chevallard, Y. (1992). Concepts fondamentaux de la didactique : perspectives apportées par une approche anthropologique. Recherches en Didactique des Mathématiques, 12(1), 77 111.

Dörfler, W. (1993). Computer use and views of the mind. In C. Keitel \& K. Ruthven (Eds.) Learning from Computers: Mathematics Education and Technology. Berlin: Springer.

Drijvers, P., \& Gravemeijer, K. (2005). Computer algebra as an instrument: Examples of 
algebraic schemes. In D. Guin, K. Ruthven, \& L. Trouche, op. cit. (pp.163-196).

Engström, L. (2004). Examples from teachers' strategies using a dynamic geometry program in upper secondary school. Paper presented at ICME-10. Retrieved December 12, 2008, from http://www.icme-organisers.dk/tsg10/articulos/Lil Engstrom.doc

Fey, J. (2006). Connecting technology and school mathematics: A review of 'The didactical challenge of symbolic calculators: turning a computational device into a mathematical instrument'. Journal for Research in Mathematics Education, 36(4), 348-352.

Fey, J., Heid, M. K., Good, R., Sheets, C., Blume, G., \& Zbiek, R. M. (1995). Concepts in algebra: A technological approach. Dedham, MA: Janson Publications, Inc.

Guin, D., Ruthven, K., \& Trouche, L. (Eds.) (2005). The didactical challenge of symbolic calculators: turning a computational device into a mathematical instrument. New York: Springer.

Haggarty, L., \& Pepin, B. (2002). An investigation of mathematics textbooks and their use in English, French and German classrooms: who gets an opportunity to learn what? British Educational Research Journal, 28(4), 567-590.

Hölzl, R. (1996). How does 'dragging' affect the learning of geometry. International Journal of Computers for Mathematical Learning, 1(2), 169-187.

Howson, G. (1995). Mathematics Textbooks: A Comparative Study of Grade 8 Texts. Vancouver: Pacific Educational Press.

Hoyles, C., Foxman, D., \& Küchemann, D. (2001). A Comparative Study of Geometry Curricula. London: Institute of Education.

Hoyles, C., \& Noss, R. (2003). What can digital technologies take from and bring to research in mathematics education? In A. J. Bishop, M. A. Clements, C. Keitel, J. Kilpatrick \& F. K. S. Leung (Eds.), Second International Handbook of Mathematics Education. Dordrecht: Kluwer.

Kaiser, G. (2002). Educational philosophies and their influence on mathematics education an ethnographic study in English and German mathematics classrooms. Zentralblatt für Didaktik der Mathematik, 34(6), 241-257.

Kendal, M., \& Stacey, K. (2001). The impact of teacher privileging on learning differentiation with technology. International Journal of Computers for Mathematical Learning, 6(2), 143-165.

Kendal, M., Stacey, K., \& Pierce, R. (2005). The influence of a computer algebra environment on teachers' practice. In D. Guin, K. Ruthven, \& L. Trouche, op. cit. (pp. 83112).

Kline, R., \& Pinch, T. (1999). The social construction of technology. In D. MacKenzie \& J. Wajcman (Eds.), The Social Shaping of Technology. Buckingham: Open University Press.

Laborde, C. (2001). Integration of technology in the design of geometry tasks with CabriGeometry. International Journal of Computers for Mathematical Learning, 6(3), 283-317.

Lagrange, J. B. (2001). L'intégration des instruments informatiques dans l'enseignement: une approche par les techniques. Educational Studies in Mathematics, 43(1), 1-30.

Lagrange, J.-B., \& Caliskan-Dedeoglu, N. (in press). Usages de la technologie dans des conditions ordinaires: Le cas de la géométrie dynamique au collège: Potentialités, attentes, pratiques. Recherches en Didactique des Mathématiques.

Lampert, M. (1993). Teachers' thinking about students' thinking about geometry: The effects of new teaching tools. In J. Schwartz, M. Yerushalmy, \& B. Wilson (Eds.), The Geometric Supposer: What is it a case of? Hillsdale NJ: Lawrence Erlbaum.

Lins, B. (2003). Actual meanings, possible uses: Secondary mathematics teachers and Cabrigéomètre. Paper presented at the Third Congress of the European Society for Research in 
Mathematics Education [CERME-3]. Retrieved December 12, 2008, from http://fibonacci.dm.unipi.it/ didattica/CERME3/proceedings/Groups/TG9/TG9_Lins cerm e3.pdf.

Pea, R. D. (1985). Beyond amplification: Using the computer to reorganize mental functioning. Educational Psychologist, 20(4), 167-182.

Rabardel, P. (2002). People And Technology: a cognitive approach to contemporary instruments. Retrieved December 12, 2008, from http://ergoserv.psy.univ-paris8.fr/.

Rabardel, P., \& Bourmaud, G. (2003). From computer to instrument system: a developmental perspective. Interacting with Computers, 15, 665-691.

Rabardel, P., \& Waern, Y (2003). From artefact to instrument. Interacting with Computers, $15,641-645$.

Remillard, J. (2005). Examining key concepts in research on teachers' use of mathematics curricula. Review of Educational Research, 75(2), 211-246.

Ruthven, K. (2002). Instrumenting mathematical activity: Reflections on key studies of the educational use of computer algebra systems. International Journal of Computers for Mathematical Learning, 7(3), 275-291.

Ruthven, K., Hennessy, S., \& Deaney, R. (2008). Constructions of dynamic geometry: A study of the interpretative flexibility of educational software in classroom practice. Computers and Education, 51(1), 297-317.

Scher, D. (2000). Lifting the curtain: The evolution of the Geometer's Sketchpad. The Mathematics Educator, 10(1), 42-48.

Trouche, L. (2004). Managing the complexity of human/machine interactions in computerized learning environments: Guiding students' command process through instrumental orchestrations. International Journal of Computers for Mathematical Learning, 9(3), 281307.

Trouche, L. (2005). Instrumental genesis, individual and social aspects. In D. Guin, K. Ruthven, \& L. Trouche, op. cit. (pp. 197-230).

Wertsch, J. (1990). The Voice of Rationality in a Sociocultural Approach to Mind. Cambridge: Cambridge University Press.

Williams, R., \& Edge, D. (1996). The social shaping of information and communications technologies. Research Policy, 25(6), 856-899.

Wiske, M. S., \& Houde, R. (1993). From recitation to construction: Teachers change with new technologies. In J. Schwartz, M. Yerushalmy, \& B. Wilson (Eds.), The Geometric Supposer: What is it a case of? Hillsdale NJ: Lawrence Erlbaum. 